\title{
Lead in the Japanese living environment
}

\author{
Jun Yoshinaga
}

Received: 26 August 2011/Accepted: 23 March 2012/Published online: 19 April 2012

(C) The Japanese Society for Hygiene 2012

\begin{abstract}
Lead has long been known to be a neurotoxic heavy metal, particularly in the context of occupational health. However, its adverse effect on the cognitive development of children at lower exposure levels has only recently received attention. Although the exposure level of contemporary Japanese children is among the lowest in the world, it is desirable to reduce exposure as much as reasonably possible due to the absence of a threshold of exposure for adverse effects. In this review, information on lead levels in milieus of our proximate environment, such as the atmosphere, drinking water, soil, house dust, diet and others, of contemporary Japan was compiled with the aim of updating our knowledge on lead distribution. Monitoring data demonstrates that lead concentrations in the atmosphere and lead intake from food consumption have decreased substantially from the 1970s. Lead was hardly detectable in tap water in a recent nation-wide monitoring survey. To the contrary, elevated lead concentrations were detected in surface soil and house dust in one of the studies on daily exposure to lead from all potential sources, and both of these sources were regarded by the authors as significant contributors of lead exposure to general Japanese children. A similar study indicated that diet is the sole major source of lead for Japanese children. A significant difference was present in the estimated dietary lead intake levels in different studies, resulting in significant discrepancies in the current knowledge on lead in our environment. Further studies are warranted to identify the major source(s) of lead exposure in Japanese children in order to
\end{abstract}

J. Yoshinaga $(\bowtie)$

Department of Environmental Studies, University of Tokyo,

Kashiwanoha 5-1-5, Kashiwa, Chiba 277-8563, Japan

e-mail: junyosh@k.u-tokyo.ac.jp establish an effective countermeasure to reduce lead exposure to children.

Keywords Lead · Environment $\cdot$ Children ·

Daily exposure $\cdot$ Exposure source

\section{Introduction}

Lead is a typical toxic heavy metal, and its toxic effects on humans have been well characterized in a number of poisoning cases in occupational and environmental settings. Owing to effective regulations and restrictions, lead exposure levels have notably decreased in recent decades, and lead poisoning cases are now only rarely reported. Alternatively, however, a small but significant adverse effect on the neurobehavioral development of children due to low-level lead exposure has been the focus of more public concern. The vulnerability of children to lead toxicity is probably due to their higher gastrointestinal absorption rate (40 vs. $10-15 \%$ in adults [1]) during the period of neuronal development. In 1991, the Centers of Disease Control of the USA (US CDC, currently Centers for Disease Control and Prevention) lowered the action level for blood lead for children from 25 to $10 \mu \mathrm{g} / \mathrm{dL}$ and currently advises starting appropriate actions to lower the lead exposure level of the child when his/her blood lead level exceeds this level. However, a number of recent epidemiologic studies indicate adverse effects, such as lowered IQ or poorer academic achievement or development indices, in children with a blood lead level well below this recommended action level [2-4]. The average blood lead level of Japanese children in the 21 st century has been reported to be $<2 \mu \mathrm{g} / \mathrm{dL}[5,6]$, which is among the lowest in the world [6]. However, based on separate pooled 
analyses, both Schwartz [7] and Lamphear et al. [8] suggested that the threshold blood lead level for the effect on children's IQ was not observable. Although the validity of this hypothesis is controversial, it would be an appropriate measure to lower the blood lead level of children as much as reasonably possible because health benefit of lead is not known. To this end, the sources of lead in Japanese milieus, particularly those of children, have to be identified as only then will it be possible to implement countermeasures for risk management.

Little information is available on the level and source(s) of lead in our living environment to which general Japanese people are exposed daily. This review focuses on the lead levels in the environmental milieus of the general Japanese population. Particular focus is placed on the environmental milieus that are potential sources of lead to children, who represent the most susceptible subpopulation to lead toxicity. The source(s) of lead in the milieus is also discussed.

In this review, data obtained in Japan and published in 2000 and later are mainly presented. The relevance of lead levels in the environmental milieus of the more distant past or that of other countries is uncertain because environmental lead levels are highly dependent on the locality and period of time. This geographical and temporal variation is mainly due to the intensity and period of the usage of leaded gasoline and lead-based paint, the two major sources of lead contamination in the world. This review is an update of the data compiled and reviewed by Nakanishi et al. [9], and the readers are referred to this latter article for further information.

\section{Lead in atmosphere}

Until the mid-1970s the lead concentration in the atmosphere of Japan was relatively high due to the use of leaded gasoline. Following the phase-out of leaded gasoline (1975 for regular gasoline and 1986 for high-octane gasoline), the atmospheric lead concentration decreased remarkably. Figure 1 shows the trend of atmospheric lead concentration in central, suburban and background Tokyo from 1969 to 2000 [10]. The observed trend was similar in other regions of Japan and corresponds to the worldwide trend that human lead exposure level, as represented by blood lead concentration, decreased with decreasing atmospheric lead concentration following the phase-out of leaded gasoline [11].

During the last decade, atmospheric lead concentration in Japan has decreased still further, as shown in Fig. 2 [12]. In this figure, the geometric mean concentrations of annual mean atmospheric lead concentrations of five monitoring stations located in Tokyo are plotted for the year 2000,

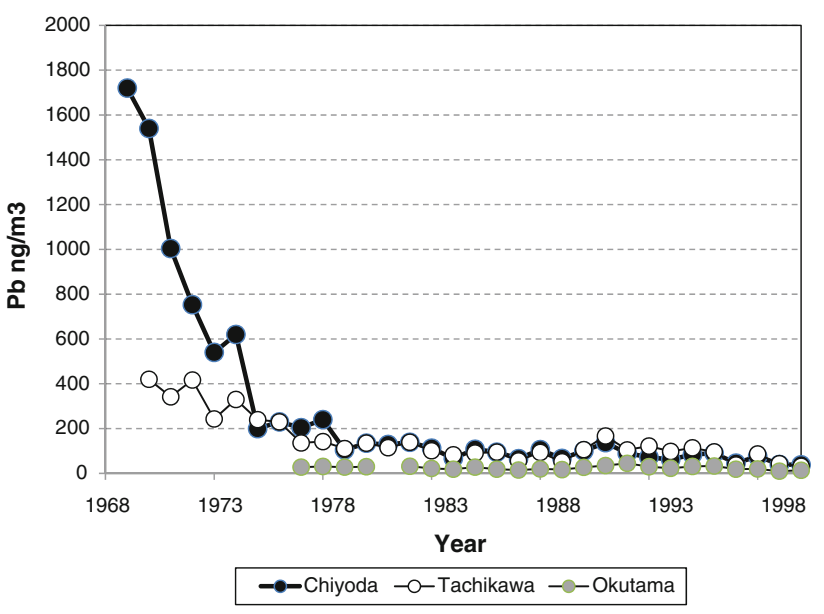

Fig. 1 Temporal trend of atmospheric lead concentration in areas of Greater Tokyo (Chiyoda, Tachikawa, Okutama). Data source: Tokyo Metropolitan Research Institute [10]

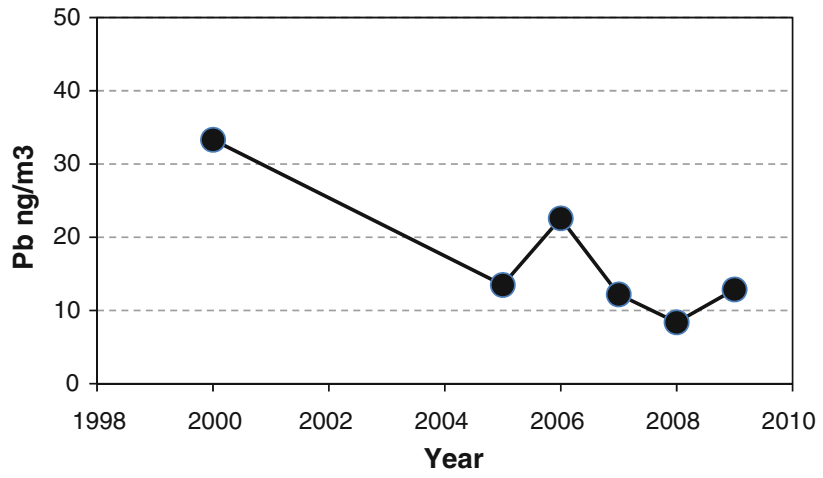

Fig. 2 Trend of atmospheric lead concentrations in Greater Tokyo after the year 2000. Data source: Tokyo Metropolitan Government [12]

while those of three other stations also located in Tokyo are plotted for 2005-2009. This trend holds true for other regions of Japan, as partly shown in Nakanishi et al. [9]. These latter authors ascribed this trend to the introduction of new regulatory measures for waste incineration facilities in the late 1990s, which were suspected to be one of the major sources of atmospheric lead in Japan [13]. Of the three monitoring stations used to collect the 2005-2009 data in Fig. 2, two were at a major cross-road and the other was in a residential area. The geometric mean concentrations during this period were 14 and $13 \mathrm{ng} / \mathrm{m}^{3}$ for the crossroad stations, respectively, and $14 \mathrm{ng} / \mathrm{m}^{3}$ for the residential area. This absence of a difference in atmospheric lead concentration between the cross-road and residential area stations suggests that automobiles are not the major source of lead in the atmosphere of Tokyo at the present time. The latest monitoring data on atmospheric lead levels in other regions of Japan are similar to, or slightly higher than those level found in Tokyo, i.e., $10-30 \mathrm{ng} / \mathrm{m}^{3}$ [14-18], although 
many local governments no longer publish monitoring data on atmospheric lead levels.

Although the atmospheric lead level has been significantly decreasing in Japan, even lower atmospheric concentrations have been reported in other countries. In 2004, the annual average lead concentration in 15 countries of the European Union ranged from 0.63 to $12.8 \mathrm{ng} / \mathrm{m}^{3}$ [19]. It may be interesting to cite that an atmospheric lead concentration of $0.076 \mathrm{ng} / \mathrm{m}^{3}\left(76 \mathrm{pg} / \mathrm{m}^{3}\right)$ was reported in Antarctica [20], which is among the lowest reported. Thus, a significant portion of lead in the Japanese atmosphere can still be considered to be anthropogenic in origin. Part of this anthropogenic lead might be from countries other than Japan, based on lead isotopic evidence [21] that was recently re-confirmed by a simulation study [22].

Indoor air may constitute a much more important source of air pollutants, including lead, to the Japanese general population because Japanese spend much more time indoors than outdoors. However, lead concentrations in the indoor air of Japanese residences have not been reported to date. Comparisons of the lead concentration in residential indoor and outdoor air in the USA and Sweden demonstrated that the concentration of lead in indoor air was approximately $20 \%$ lower [23-26]. Whether this holds true in Japan should be examined. In one study, the indoor air lead concentration of residences with smokers was higher than that in residences without smokers [27], indicating environmental tobacco smoke is one of the source(s) of lead in indoor air. The blood lead concentration of Japanese children with a smoking family member who smokes in front of the children was higher than that without such a family member $[5,6]$, indicating that passive smoking is a significant source of lead exposure to children.

\section{Lead in drinking water}

Lead concentration in tap water supplied in Japanese municipals are mostly non-detectable $(<0.001 \mathrm{mg} / \mathrm{L})$. According to the routine tap water quality survey carried out throughout Japan in 2008, only five of 5,256 tap water samples exceeded the drinking water quality standard $(0.01 \mathrm{mg} / \mathrm{L})$, and annual mean concentrations were $<0.001 \mathrm{mg} / \mathrm{L}$ in $99.8 \%$ of the samples (Table 1) [28]. Therefore, tap water is not considered to be a significant source of lead exposure to the general Japanese population.
However, some tap water can contain elevated concentrations of lead leached from lead pipes, which were widely used in Japan in the past. Although lead pipes are replacing stainless, polyvinylchloride or polyethylene pipes that do not leach lead, a significant number of households are still supplied with water through lead pipes, and elevated lead concentrations have been found in some tap water samples. Based on their review of several reports in Japan, Nakanishi et al. [9] concluded that (1) the lead concentration in tap water of residences with lead pipes increases with the length of lead pipe installed, and (2) the lead concentration in tap water present in pipes overnight decreases after flushing for a given period of time.

The lead concentrations in bottled drinking water (BDW) sold commercially in Japan have also been reported. Suzuki et al. [29] analyzed 170 BDW of domestic and foreign origin and found lead concentration ranging from $<0.0010$ to $0.0078 \mathrm{mg} / \mathrm{L}$. Sasaki et al. [30] detected lead in one of 61 BDW (0.00142 mg/L: detection limit unspecified).

Shotyc and Krachler [31] analyzed lead in 125 brands of BDW from 28 countries (including Japan) using an ultra-clean laboratory method and found that the median concentration was $0.0000085 \mathrm{mg} / \mathrm{L}$ (range: $<0.000001-0.000761 \mathrm{mg} / \mathrm{L}$ ), which was lower than that reported previously. They suggested that some of the measurements of low-level lead in drinking water made in some of the earlier studies suffered from analytical problems. Generally speaking, the analysis of lead in drinking water samples may not be straightforward because the concentration is generally low $(<0.001 \mathrm{mg} / \mathrm{L})$ and contamination during the analytical procedure is likely: strict contamination-control is indispensable to obtain reliable results. Therefore, this analytical pitfall should be taken into consideration when data on lead concentrations in drinking water samples, as well as other samples with lower lead concentrations, such as dietary sources, are being evaluated. With their sophisticated analytical technique, Shotyc and Krachler [31] found that lead concentrations in BDW in glass bottles $(0.000154-0.000261 \mathrm{mg} / \mathrm{L})$ were higher than those in polyethylene terephthalate (PET) bottles (0.000040-0.0000 $87 \mathrm{mg} / \mathrm{L}$ ), probably due to the leaching of lead from the glass container.

\section{Lead in soil}

In the past, exposure to contaminants present in the soil was considered by Japanese government to occur through

Table 1 Distribution of lead concentration in tap water samples in Japan

\begin{tabular}{lllllllllllll}
\hline Concentration $(\mathrm{mg} / \mathrm{kg})$ & $\leq 0.001$ & $\leq 0.002$ & $\leq 0.003$ & $\leq 0.004$ & $\leq 0.005$ & $\leq 0.006$ & $\leq 0.007$ & $\leq 0.008$ & $\leq 0.009$ & $\leq 0.01$ & $>0.01$ & Total \\
\hline Number of samples & 4,868 & 198 & 71 & 40 & 24 & 21 & 11 & 11 & 7 & 4 & 1 & 5,256
\end{tabular}

Data source: Database of Water Quality of Aqueduct, 2008: http://www.jwwa.or.jp/mizu/index.html 
the drinking of groundwater in such soil and the consumption of crops and vegetables grown on such soil. Recently, in addition to this classic contamination route, the direct ingestion of, and dermal contact with contaminated soil particles have also been recognized as significant routes of exposure. Direct ingestion can take place unintentionally by swallowing soil particles that adhere to the hand and/or, probably, by ingesting soil particles $(>10 \mu \mathrm{m})$ expelled from the upper respiratory system after breathing in re-suspended particles in the air. The notion that contaminants in the soil can be a source of direct human exposure has become recognized in the past decade in Japan, although it was recognized much earlier in other countries.

Based on an analysis of 514 soils from 78 sites of forest and agricultural fields across Japan, the background concentration of lead in soil in Japan has been estimated and the median lead concentration determined to be $20 \mathrm{mg} / \mathrm{kg}$ (range $1.0-1,100 \mathrm{mg} / \mathrm{kg}$ ) [32]. Variation in lead concentration due to soil type was small. This soil analysis was based on total dissolution of the samples (particle size unspecified) in a $\mathrm{HNO}_{3} / \mathrm{HClO}_{4} / \mathrm{HF}$ mixture.

The lead concentration in the soil of ten Japanese cities was measured by the Environment Agency of Japan [33]. A total of 193 surface $(0-5 \mathrm{~cm})$ soil samples from playgrounds, school yards, temple/shrine yards and other places in these cities, all locations where children were likely to be exposed, were analyzed for lead after $\mathrm{HNO}_{3} / \mathrm{HCl}$ dissolution of $<2-\mathrm{mm}$ fraction. Note that this digestion could not extract lead in the silicate phase, if present, because silicate can only be decomposed by acid mixture containing HF. Table 2 shows the results according to the sampling site. The overall median concentration of 193 samples was $13.0 \mathrm{mg} / \mathrm{kg}$ (range $1.6-141 \mathrm{mg} / \mathrm{kg}$ ). Lead concentrations in surface soils in large cities, such as Tokyo and Osaka, were higher than those in smaller cities.

Soil in the playground carries particular importance when children's exposure to lead in soil is being considered. Aung et al. [34] measured lead concentrations in surface (approx. $1 \mathrm{~cm}$ ) soils and sands from 25 playgrounds in Tokyo after $\mathrm{HNO}_{3} / \mathrm{HClO}_{4} / \mathrm{HF}$ digestion. The arithmetic mean lead concentration in sand from sandpits was 13.6 (range $7.41-36.5$ ) and $25.4 \mathrm{mg} / \mathrm{kg}(11.7-62.5 \mathrm{mg} / \mathrm{kg}$ ) for the $<2-\mathrm{mm}$ and $<149-\mu \mathrm{m}$ fractions, respectively. In comparison, that of play area soils was $55.1(8.86-245)$ and $67.3 \mathrm{mg} / \mathrm{kg}(15.7-248 \mathrm{mg} / \mathrm{kg})$, respectively. Takaoka et al. [35] also analyzed lead in 91 surface soil samples $(<150-\mu \mathrm{m}$ fraction) of 31 playgrounds in a ward in Tokyo using the identical analytical method to Aung et al. [34]; the median concentration was $40.5 \mathrm{mg} / \mathrm{kg}$ (range $15.2-237 \mathrm{mg} / \mathrm{kg}$ ). Lead concentrations in these two studies seem to be higher than those in soils from Tokyo analyzed in the abovementioned survey by the Environment Agency (median lead concentration $19.1 \mathrm{mg} / \mathrm{kg}$; range $4.1-141 \mathrm{mg} / \mathrm{kg}$ ). This difference may be due to two factors: (1) particle size of the soil analyzed-it is well known that higher concentrations of pollutants are found in finer particle fractions; (2) the digestion method-as mentioned earlier, the digestion of soil sample with HF destroys silicate in the soil and extracts all of lead.

Takaoka et al. [35] estimated the source of lead in playground surface soil in Tokyo, and their results suggest that the anti-corrosive paint applied on the metallic playing equipment is one of the sources: the lead concentration in a $2 \times 2-m$ grid of surface soil with metallic playground equipment was higher than that in grids without playground equipment (Fig. 3). The issue of paint on playground equipment was first pointed out by Irie et al. [36] who reported the lead concentration in paint chips from playing equipment in the yards of nursery schools and schools in Yamaguchi Prefecture. Paint chips found on the surface soil in Tokyo playgrounds contained $0.002-16 \%$ lead [34, 35]. In 2002, the Tokyo Metropolitan Government advised the use of lead-free anti-corrosive paint and pigment for the playing equipment as a part of Lead Guideline for Children [37]. Based on the results of their stable lead isotope analysis, Takaoka et al. [35] also indicated that the deposition of gasoline-related lead in the past is another source of lead in the surface soil of playgrounds in contemporary Tokyo.

\section{Lead in house dust}

House dust has long been known to be a significant exposure source of lead in the USA, particularly for

Table 2 Lead concentrations in soil samples from ten Japanese cities of Japan

\begin{tabular}{lllll}
\hline Variables & Sample site & & & Total \\
\cline { 2 - 5 } & Playground & School yard & Temple/shrine & Others \\
\hline Number of samples & 101 & 32 & 19 & 41 \\
Median (mg/kg) & 12.2 & 8.9 & 19.5 & 13.9 \\
Min-max (mg/kg) & $2.1-141$ & $4.4-97.2$ & $2.5-79.7$ & $1.6-130$ \\
\hline
\end{tabular}

Determined after $\mathrm{HNO}_{3} / \mathrm{HCl}$ dissolution of $<2 \mathrm{~mm}$ particle fractions. Data source: Environment Agency of Japan [32] 


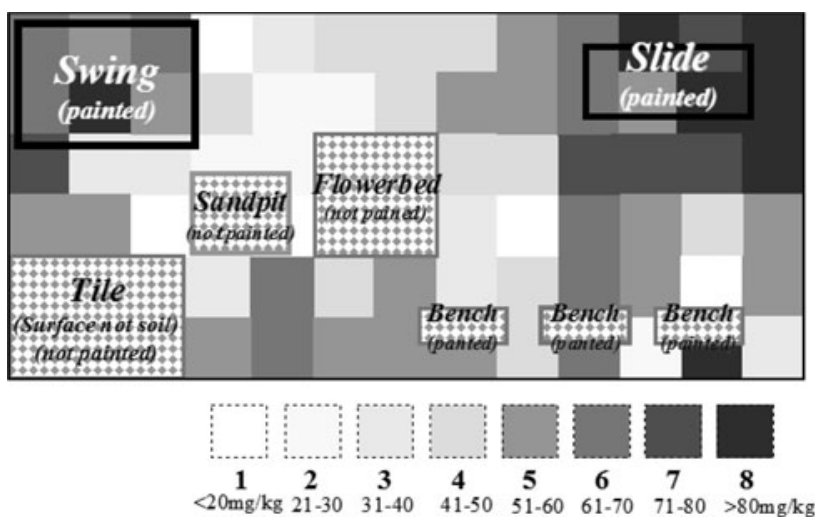

Fig. 3 Distribution of lead concentration in the surface soil of a playground in Tokyo. The playground area was divided into $2 \times 2-\mathrm{m}$ grids, and the lead concentration was determined in the soil collected from the center of the grid. Reproduced from Takaoka et al. [35] with permission

children [38]. The underlying reason for this is childhood lead poisoning due to the extensive use of lead-based paint in the U.S. residences until the 1970s and the ingestion of paint chips or house dust contaminated with paint chips peeled off from the deteriorated surface; this has continued even up to the present time [39]. House dust is also regarded as a significant source of lead to adults [40]. Consequently, the levels and sources of variation of house dust lead content have been examined in a number of studies in many countries. However, lead in house dust has not attracted much attention in Japan, probably because lead-based paint has not been extensively used in Japanese residences.

Aung et al. [41] were the first to point out that house dust could be a significant source of lead in contemporary Japanese children based on their measurement of 21 house dust samples collected from residences in Tokyo Metropolitan Area. The average lead concentration in 21 vacuum cleaner dust samples was reported to be $117 \mathrm{mg} / \mathrm{kg}$ (arithmetic mean) for the $<150-\mu \mathrm{m}$ fraction. This mean concentration was lower than those reported in the literature in the 1980s (e.g., [42]). Nakanishi et al. [9] assumed much lower lead level $(13 \mathrm{mg} / \mathrm{kg})$ in house dust in their estimation of lead intake of Japanese children.

Figure 4 presents a histogram of lead concentration in house dust prepared from the vacuum cleaner dust collected in 108 residences in Japan. The data are the compilation of the results of surveys in the author's laboratory [41, 43-46], and to the best of this author's knowledge no other data have ever become available in Japan. The distribution was of a log-normal type with a large variation: the minimum, median and maximum concentration was $18.0,83.2$ and $1,800 \mathrm{mg} / \mathrm{kg}$, respectively and the geometric mean concentration was $97.8 \mathrm{mg} / \mathrm{kg}$. Note that the concentration was measured after $\mathrm{HNO}_{3} / \mathrm{HF} / \mathrm{HClO}_{4}$ digestion

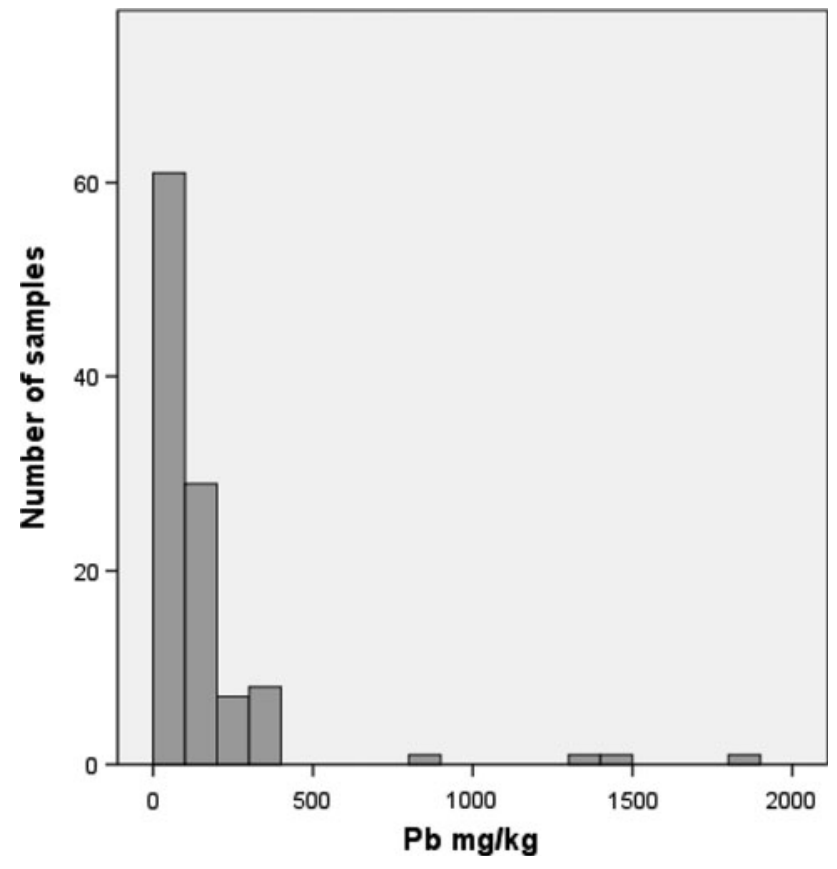

Fig. 4 Lead concentration in house dust samples. House dust was prepared from vacuum cleaner dust [41, 43-46]

of the $<250-\mu \mathrm{m}$ fraction of vacuum cleaner dust samples. This figure includes $<150 \mu \mathrm{m}$ data in the Aung et al. study because Nakamura et al. [43] indicated that lead concentrations in vacuum cleaner dust samples of 100-250-, $53-100-$ and $<53-\mu \mathrm{m}$ fractions did not significantly differ.

Table 3 compares the lead concentration in house dust (vacuum cleaner dust) in Japan with relevant data retrieved from more recently published reports referring to other countries [47-51]. This table shows that lead concentration in house dust from Japanese residences is lower than the international average. It is noted that the average lead concentration of house dust in the USA, New Zealand and European countries in the 1980s, as compiled by Fergusson and Kim [42], ranged from 140 to $11,000 \mathrm{mg} / \mathrm{kg}$ and was were much higher than the values presented in Table 3.

The source of lead in house dust of Japanese residences is not fully known. House dust can be regarded as a mixture of track-in soil and airborne particles and of organic matter generated in indoor [52]. Ishibashi et al. [44] sampled a set of house dust, garden soil and outdoor dust (windowsill dust) samples from 41 residences in 19 prefectures of Japan and measured the lead concentration in the $<250 \mu \mathrm{m}$ fraction after $\mathrm{HNO}_{3} / \mathrm{HClO}_{4} / \mathrm{HF}$ digestion. As shown in Fig. 5, the lead concentration was in the order of soil (geometric mean $34.7 \mathrm{mg} / \mathrm{kg}$ ) < house dust $(65.5 \mathrm{mg} /$ $\mathrm{kg})<$ outdoor dust $(166 \mathrm{mg} / \mathrm{kg})$, indicating that the contribution of soil to house dust lead was small. The positive correlation between the concentration of lead in house dust and that in soil or outdoor dust for these residences was marginally significant. Nakamura et al. [43] carried out 
Table 3 Comparison of geometric mean lead concentration in house dust from Japanese residences and those from other countries

\begin{tabular}{lclllcl}
\hline Country & $n$ & Total/extract ${ }^{\mathrm{a}}$ & $\begin{array}{l}\text { Particle } \\
\text { size }(\mu \mathrm{m})\end{array}$ & $\begin{array}{l}\text { Geometric } \\
\text { mean }(\mathrm{mg} / \mathrm{kg})\end{array}$ & $\begin{array}{l}\text { Range } \\
(\mathrm{mg} / \mathrm{kg})\end{array}$ & Reference \\
\hline Japan & 108 & Total & $<150$ and $<250$ & 97.8 & $18-1,800$ & This study \\
UK & 32 & Extract & $<63$ & 150 & $56.8-358$ & Turner and Simmonds [47] \\
Australia & 82 & Extract & $<100$ & 85.2 & $16-16,600$ & Chattopadhyay et al. [48] \\
Canada & 48 & Total & $100-250$ & 233 & $50.2-3,226$ & Rasmussen et al. [49] \\
Hong Kong & 151 & Extract & $<250$ & $157^{\mathrm{b}}$ & $0.1-1,415$ & Tong and Lam [50] \\
Poland & 23 & Total & $63-125$ & 131 & $64-318$ & Liciewicz et al. [51] \\
& & & $32-63$ & 158 & $80-318$ & \\
\end{tabular}

a Analysis of lead involving HF digestion or X-ray fluorescence spectrometry was denoted as "total". Analysis of lead in acid (other than HF) leached house dust was denoted as an "extract"

b Median

multi-element analysis of house dust from Japanese residences and analyzed the result by factor analysis, ultimately extracting four factors with an eigenvalue of $>1$ which explained $73 \%$ of the variation. A large loading of lead $(0.721)$ was found on the third factor along with chromium, barium, sulfur and titanium. This factor was inferred to be the factor of paint because the other elements are known to be major constituents of pigment. Moderate loading was found on other factors as well, i.e., factor of soil and factor of heavy metal. Although paint was suggested as one of the sources, it is not residential paintwhich has been found to be a well-known contaminant of house dust in the USA and other countries-because Japanese do not have the custom of painting their residence. Thus, it may be speculated that the paint is from various painted products, such as furniture, toys, accessories or ornaments, in the home.

\section{Lead in foods}

Lead levels in foods are measured in the context of regulating food hygiene by local governmental institutes in Japan; however, as reviewed by Nakanishi et al. [9], lead levels are mostly undetectable and therefore not informative for use in the quantitative estimation of lead intake by the Japanese people. Figure 6 shows a comparison of the mean lead concentrations in food categories based on the measurements of 94,126 food samples in 15 European countries in 2003 and later [53]. Note that food category is based on the European Food Safety Authority categorization and that the lower bound mean values (concentration zero was substituted for undetectable sample) are shown in this figure for the relative presentation of average lead levels of foods in these categories. As can be seen from this figure, variation in the mean lead concentration of the different food categories $(0.0052-0.3652 \mathrm{mg} / \mathrm{kg})$ is moderate. A higher mean lead concentration is observed for some categories, which includes dried foods, such as coffee or cocoa beans/powder and tea leaves ("coffee, tea and cocoa"), or dried herbs and spices ("miscellaneous"). The higher lead concentration of "meat and meat products" is because this category includes game meat, which is assumed to be contaminated by lead shot. When these exceptions are excluded, somewhat higher levels are found for vegetables and fish. Although the data presented in Fig. 6 are based on a large number of food samples, it may be biased due to the inclusion of products with an extremely high lead content but which account for an insignificant contribution in terms of daily consumption. Therefore, the total diet study (TDS) approach is considered to better represent food-derived lead intake.

Since 1977, dietary lead intake levels have been monitored by several local governmental institutes based on the analysis of total diet, and the results of these studies have been compiled and published by the National Institute of Health Sciences (NIHS) [54]. This TDS was based on the market basket method. According to these data, the estimated daily dietary intake of lead has been decreasing since 1977/1978 (100 $\mu \mathrm{g} /$ day), but plateau seems to have been reached after 2000: mean daily lead intake between 2000 and 2007 was $22.9 \pm 4.5 \mu \mathrm{g} /$ day (range 17.6-32.0 $\mu \mathrm{g}$ /day) [54]. Ohno et al. [55] also carried out a survey on lead intake from foods in six Japanese cities by the market basket method. The estimated dietary intake of lead was $44.4 \pm 18.1 \mu \mathrm{g} /$ day. The food category which contributed to most to daily lead intake was "rice" $(9.1 \pm 5.9 \mu \mathrm{g} /$ day $)$ and "alcohol and beverage" ( $8.7 \pm 1.1 \mu \mathrm{g} /$ day $)$ followed by "other vegetables and seaweed" $(4.3 \pm 2.9 \mu \mathrm{g} / \mathrm{day})$ and "cereals and potatoes" $(4.1 \pm 2.9 \mu \mathrm{g} / \mathrm{day})$.

Lower estimates of dietary lead intake levels have been reported in other sets of surveys. Aung et al. [56] measured 

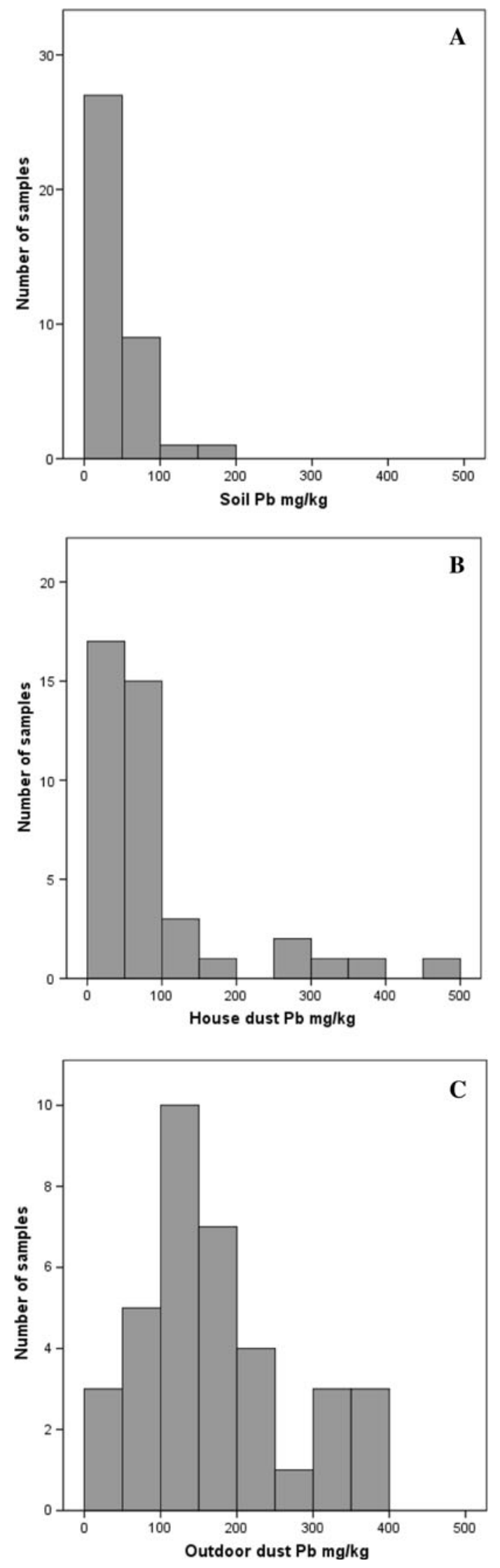

Fig. 5 Comparison of lead concentration in the soil, house dust and outdoor dust. A set of garden soil (a), house dust (b) and outdoor dust (c) samples was collected from 41 households in Japan [44]

dietary lead intake of mother/child pairs living in Tokyo and Saitama. Duplicated diet samples that included tap water were collected for 7 consecutive days from all mother/child pairs of 33 households in 2001 as a part of survey of Environment Agency of Japan on the ingestion of soil particles by children. The mean lead intake of the 33 children, calculated from lead concentrations in, and measured weight of the homogenized 7-day diet samples, was 5.34 and that for mothers was $6.74 \mu \mathrm{g} / \mathrm{day}$; both values are much lower than the NIHS data. The lead intake of children was also measured in a duplicated portion study carried out in Shizuoka during 2008-2010. The mean daily lead intake level of eight children (including tap water) was reported to be $6.1 \mu \mathrm{g} /$ day (range $2.4-13.9 \mu \mathrm{g} / \mathrm{day}$ ), with utmost caution having been taken to prevent contamination during analysis [46]; this level is consistent with the data presented by Aung et al. [56].

The large discrepancy between dietary lead intake values obtained by market basket method and those obtained by the duplicated diet method may be due to actual differences due to subject population, as shown by Niisoe et al. [57], or to some technical artifact(s).

\section{Lead in other materials}

An early study by Kaniwa et al. [58] reported elevated lead concentrations in various stationery products used in Japan: these authors detected $>0.06 \%$ lead in three of 49 pigments used in pencils (range 0.0003-6.52\%) and in three of 54 water color pigments (range 0.0002-0.228\%), while they found that not one of 55 wax crayons tested contained $>0.06 \%$ lead. They also measured the lead concentration of commercial paints sold at that time (1981) and found that ten of the 31 paints measured contained lead levels of $>0.06 \%$ (range $0.0001-11.6 \%$ ). Of 68 paint chips taken from buildings for testing, 19 contained lead levels of $>0.06 \%$ (up to $13.4 \%$ ). Although the data were published in 1981, further testing of stationery products in common use should be performed to determine if they still contain elevated lead levels because these can be important ingestion sources for school children.

Lead concentrations in baby toys sold in Japanese market were measured by Kawamura et al. in 2006 [59]. Most of these toys were made of synthetic resin, such as polyvinylchloride. The lead content of five toy samples (range $1.5-1,300 \mathrm{mg} / \mathrm{kg}$ ) of the 45 measured was above detection limit $(1.5 \mathrm{mg} / \mathrm{kg})$. The migration test of International Organization for Standardization (ISO 8124-3) (extraction at $37{ }^{\circ} \mathrm{C}$ for $2 \mathrm{~h}$ with $0.07 \mathrm{~mol} / \mathrm{L} \mathrm{HCl}$ ) did not 
Fig. 6 Comparison of average lead concentration in food products belonging to 15 categories from European countries. Data source: European Food Safety Authority [53]

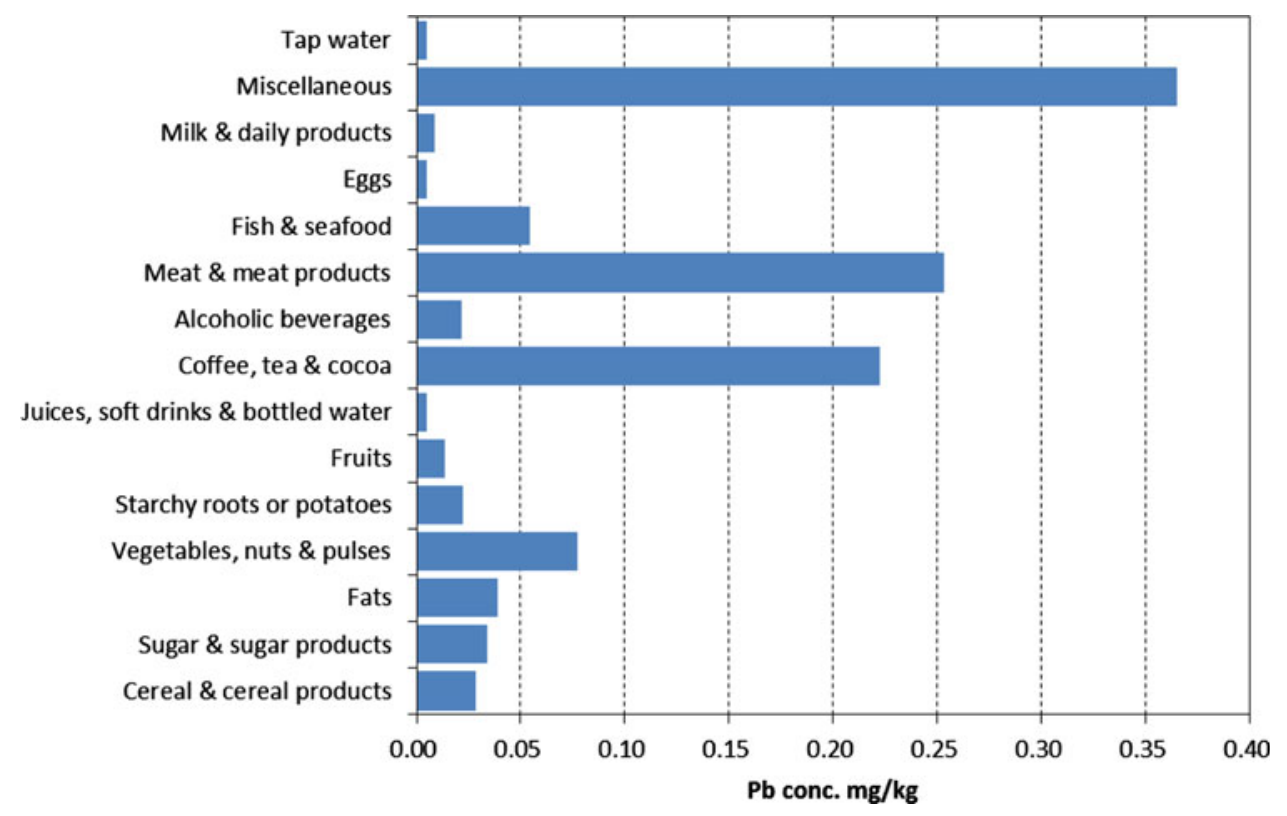

identify any toys with lead migration that exceeded the ISO limit $(90 \mathrm{mg} / \mathrm{kg}$ ). Isama et al. applied the migration test of ISO 8124-3 to 135 household products (ornaments, accessories, stationery, etc.) made of synthetic resin sold on Japanese market [60]. These samples included smaller sized toys with the potential for being accidentally swallowed by children. Lead migration above the ISO limit was found for two products ("decoration parts" containing 1,810 and $1,660 \mathrm{mg} / \mathrm{kg}$ ) with four other products exceeding $10 \%$ of the limit. The authors estimated that if a child would accidentally swallow one piece of the product, lead intake would be more than $100 \mu \mathrm{g}$. These studies demonstrate that there are products with an elevated lead content/ migration in the home environment of children in contemporary Japan.

Some plastic bags distributed by supermarkets and other stores have been found to contain an elevated concentration of lead [61]. While none of 2,154 white and transparent plastic bags collected in Kyoto in 2007 contained a detectable concentration of lead $(<100 \mathrm{mg} / \mathrm{kg}), 17-18 \%$ of 565 colored plastic bags (brown, yellow, orange, etc.) did contain lead, sometimes up to $25,000 \mathrm{mg} / \mathrm{kg}$.

\section{Daily exposure to lead of Japanese}

Table 4 compares the estimated daily lead exposure levels to Japanese from all possible sources that have been reported in the past. To date, the results from only three have been reported, namely, the Environment Agency of Japan survey in 2000 for adults [33], the Aung et al. study in 2004 for children [41] and the Nakanishi et al. estimates of 2006 [9]. Note that the estimation methodology differs between the two former studies and the latter one. In the former two studies, average lead concentration in the exposure milieus was multiplied by the average/default ingestion (inhalation) rate to calculate the average total intake. In the latter study, the probabilistic approach was used: variations in the concentration of lead in exposure milieus, ingestion (inhalation) rate and body weight were included in the model for the estimation. Therefore, in this table, average (median or geometric mean) output data expressed as micrograms lead per unit body weight per day in the literature were converted by the author for comparison with other two exposure values. Due to the different estimation approach employed in this study, the result in Table 4 is somewhat different from the simulation results of Nakanishi et al. [9].

Data by Aung et al. [41] and Nakanishi et al. [9] were for children and thus may be comparable. Although estimated daily oral exposure levels in these studies were moderately consistent ( 21.1 and $31.2 \mu \mathrm{g} /$ day, respectively), the most striking difference was the contributions of diet and soil/house dust to total lead exposure: Aung et al. [41] estimated the contributions of house dust, diet/water and soil to be 50,25 and $25 \%$, respectively, while Nakanishi et al. [9] estimated the contributions diet, soil/house dust and water to be $83,6.7$ and $10 \%$, respectively. Contribution from air was negligible in both studies. This difference was attributable to the concentration of lead in the milieus as described in aforementioned sections. The ingestion rates assumed in the studies may also be the cause of this difference. Takagi et al. [62] recently applied high-precision stable isotope analysis to source apportionment of lead in children's blood. They preliminarily presented a case study involving two children: one child had blood lead 
Table 4 Estimated daily intake of lead in Japanese

\begin{tabular}{|c|c|c|c|c|c|c|}
\hline \multirow[t]{2}{*}{ Medium } & \multicolumn{2}{|c|}{ Environment Agency 2000 [33] (adult) } & \multicolumn{2}{|c|}{ Aung et al. 2004 [41] (children) } & \multicolumn{2}{|c|}{$\begin{array}{l}\text { Nakanishi et al. } 2006 \text { [9] (children } \\
6 \text { years) }\end{array}$} \\
\hline & $\begin{array}{l}\text { Lead } \\
\text { concentration }\end{array}$ & $\begin{array}{l}\text { Inhalation/ingestion } \\
\text { rate }\end{array}$ & $\begin{array}{l}\text { Lead } \\
\text { concentration }\end{array}$ & $\begin{array}{l}\text { Inhalation/ingestion } \\
\text { rate }\end{array}$ & $\begin{array}{l}\text { Lead } \\
\text { concentration }\end{array}$ & $\begin{array}{l}\text { Inhalation/ingestion } \\
\text { rate }^{\mathrm{a}}\end{array}$ \\
\hline Atmosphere & $0.073 \mu \mathrm{g} / \mathrm{m}^{3}$ & $15 \mathrm{~m}^{3} /$ day & $0.045 \mu \mathrm{g} / \mathrm{m}^{3}$ & $8.75 \mathrm{~m}^{3} /$ day & $0.0253 \mu \mathrm{g} / \mathrm{m}^{3}$ & $7.2 \mathrm{~m}^{3} /$ day \\
\hline Inhalation $^{\mathrm{b}}$ & $1.1 \mu \mathrm{g} /$ day & & $0.4 \mu \mathrm{g} /$ day & & $0.2 \mu \mathrm{g} / \mathrm{day}$ & \\
\hline Diet & $44 \mu \mathrm{g} /$ day & & $4.79 \mu \mathrm{g} /$ day & & NA $(28.3)^{\mathrm{d}}$ & \\
\hline $\begin{array}{l}\text { Drinking } \\
\text { water }\end{array}$ & $0.01 \mu \mathrm{g} / \mathrm{L}$ & 2 L/day & & & $\begin{array}{l}3.8 \mu \mathrm{g} / \mathrm{L} \\
2.3 \mu \mathrm{g} / \mathrm{L}\end{array}$ & $\begin{array}{l}0.28 \mathrm{~L} / \text { day } \\
0.28 \mathrm{~L} / \text { day }\end{array}$ \\
\hline Soil & $13 \mu \mathrm{g} / \mathrm{g}$ & $\begin{array}{l}0.2 \mathrm{~g} / \mathrm{day} \text { (child) } \\
0.1 \mathrm{~g} / \mathrm{day} \text { (adult) }\end{array}$ & $46.4 \mu \mathrm{g} / \mathrm{g}$ & $0.1 \mathrm{~g} /$ day & $13.2 \mu \mathrm{g} / \mathrm{g}$ & $0.087 \mathrm{~g} /$ day \\
\hline House dust & - & - & $117 \mu \mathrm{g} / \mathrm{g}$ & $0.1 \mathrm{~g} / \mathrm{day}$ & & \\
\hline Oral $^{\mathrm{c}}$ & $45.3 \mu \mathrm{g} /$ day & & $21.1 \mu \mathrm{g} / \mathrm{day}$ & & $31.2 \mu \mathrm{g} / \mathrm{day}^{\mathrm{e}}$ & \\
\hline
\end{tabular}

${ }^{a}$ Estimated ingestion rate for a 6-year-old child is given in the literature. Median or geometric mean is shown in this table

${ }^{\mathrm{b}}$ Inhalation $=$ atmospheric lead concentration $\times$ inhalation rate

c Sum of total oral exposure

${ }^{\mathrm{d}}$ Not specified in the literature. Dietary intake was calculated by subtracting lead intake from water and soil/dust from total oral intake [originally given as $1.3 \mu \mathrm{g} / \mathrm{kg}$ body weight/day (median value) which was multiplied average body weight of 6 years child as $24 \mathrm{~kg}$ ] and indicated in parenthesis

e The value was calculated by the present author by using 50 percentile values reported in Nakanishi et al. [9] in which intake or ingestion rate was expressed as distribution; therefore, this value may involve uncertainty

isotope ratios close to those of house dust of the child's household, while approximately $50 \%$ of blood lead in the other child was from house dust/soil [62]. If lead in house dust significantly contributes to the daily lead exposure of Japanese children, as indicated by Aung et al. [41] and Takagi et al. [62], some children, who live in homes with house dust with a higher lead concentration may be at risk of excessive exposure. A large-scale survey of house dust lead may therefore be warranted.

\section{Concluding remarks}

Information on the lead concentration in environmental milieus of Japan, which are potential human exposure sources, has been compiled for updating. The lead concentration in the atmosphere and diet has decreased significantly, probably due to the phase-out of leaded gasoline. An elevated lead concentration has sporadically been found in surface soil and house dust, of which the source(s) are only partially known. Identification of the source(s) of lead in soil and house dust may be of critical importance for reducing the lead exposure level of children because these have been indicated as major contributors. Toys and some products in our living environment can also be an accidental ingestion source of lead.

Although the lead exposure level of Japanese children has been found to be among the lowest in the world and apparently free from any health risk [6], the results of previous studies $[7,8]$ indicate the absence of a threshold of exposure below which no effect to cognitive development of children is expected. In this regard, the lower the lead exposure level is, the more favorable the expected development of children. Thus, we still need to clarify the major lead source(s) of lead to Japanese children; however, only a limited number of such studies have been performed to date. Moreover, the results of those few studies are not consistent: one study found a significant contribution of soil and house dust to daily lead exposure of contemporary Japanese children $(25 \%$ of total for soil and $50 \%$ for house dust) while the other indicated that diet was the major contributor $(>80 \%)$. Relative contributions from possible exposure sources are needed to establish an effective countermeasure to control lead exposure of children. Therefore, further studies are warranted to elucidate the relative contribution of diet, drinking water, soil and house dust to daily lead exposure of Japanese children.

Conflict of interest None.

\section{References}

1. World Health Organization (WHO). Environmental Health Criteria 165: inorganic lead. Geneva: WHO; 1995.

2. Surkan PJ, Zhang A, Trachtenberg F, Daniel DB, McKinlay S, Bellinger DC. Neuropsychological function in children with blood lead levels $<10 \mu \mathrm{g} / \mathrm{dL}$. NeuroToxicol. 2007;28:1170-7.

3. Miranda ML, Kim D, Galeano MAO, Paul CJ, Hull AP, Morgan SP. The relationship between early childhood blood lead levels 
and performance on end-of-grade tests. Environ Health Perspect. 2007;115:1242-7.

4. Jusko TA, Henderson CR Jr, Lanphear BP, Coly-Slechta DA, Parsons PJ, Canfield RL. Blood lead concentrations $<10 \mu \mathrm{g} / \mathrm{dL}$ and child intelligence at 6 years of age. Environ Health Perspect. 2008;116:243-8.

5. Kaji M. Blood lead levels in Japanese children-effects of passive smoking. Biomed Res Trace Elem. 2007;18:199-203.

6. Yoshinaga J, Takagi M, Yamasaki K, Tamiya S, Watanabe C, Kaji M. Blood lead levels of contemporary Japanese children. Environ Health Prevent Med. 2012;17:27-55.

7. Schwartz J. Low-level lead exposure and children's IQ: a metaanalysis and search for a threshold. Environ Res. 1994;65:42-55.

8. Lanphear BP, Hornung R, Khoury J, Yolton K, Baghurst P, Bellinger DC, et al. Low-level environmental lead exposure and children's intellectual function: an international pooled analysis. Environ Health Perspect. 2005;113:894-9.

9. Nakanishi J, Kobayashi N, Naito W. Detailed risk assessment series 9 lead (in Japanese). Tokyo, Maruzen; 2006. English version available at: http://www.aist-riss.jp/projects/RAD/download01. cgi?Lead_e.

10. Tokyo Metropolitan Research Institute. Measurement data of atmospheric suspended particle matters and other pollutants (in Japanese).Tokyo: Tokyo Metropolitan Research Institute; 2001.

11. Thomas VM, Socolow RH, Fanelli JJ, Spiro TG. Effects of reducing lead in gasoline: an analysis of the international experience. Environ Sci Technol. 1999;33:3942-8.

12. Tokyo Metropolitan Government. Hazardous air pollutants monitoring report (in Japanese). Tokyo: Tokyo Metropolitan Government; 2011.

13. Sakata M, Kurata M, Tanaka N. Estimating contribution from municipal solid waste incineration to trace metal concentrations in Japanese urban atmosphere using lead as a marker element. Geochem J. 2000;34:23-32.

14. Aoemori Prefecture. Hazardous air pollutants monitoring data (in Japanese). Aomori Prefecture; 2011. Available at: http://www. pref.aomori.lg.jp/nature/kankyo/yuugai_taiki.html. Accessed 30 Nov 2011.

15. Saitama Prefecture. Hazardous air pollutants monitoring data (in Japanese). Saitama Prefecture; 2011. Available at: http://www.pref. saitama.lg.jp/uploaded/attachment/428030.pdf. Accessed 30 Nov 2011.

16. Aichi Prefecture. Suspended particulate matter monitoring data (in Japanese). Aichi Prefecture; 2011. Available at: http://kankyo jyoho.pref.aichi.jp/Taiki/Taiki/taikifunjin.html. Accessed 30 Nov 2011.

17. Toyama Prefectural Environmental Science Research Center. Annual report (in Japanese). Toyama Prefecture: Environmental Science Research Center; 2010. Available at: http://www.eco. pref.toyama.jp/nenpo/nenpo.html.

18. Hiroshima Prefecture. Fiscal year 2010 Hiroshima Prefecture environment data (in Japanese). Hiroshima Prefecture; 2011. Available at: http://www.pref.hiroshima.lg.jp/eco/b/b3/de-ta_h22/ de-tasyuu22.htm. Accessed 30 Nov 2011.

19. European Monitoring and Evaluation Programme (EMEP). Heavy metals and POP measurements, 2004. Kjeller: Norwegian Institute for Air Research; 2006.

20. Maenhaut W, Zoller WH, Duce RA, Hoffman GL. Concentration and size distribution of particulate trace elements in the south polar atmosphere. J Geophys Res. 1979;84:2421-31.

21. Mukai H, Tanaka A, Fujii T. Lead isotope ratios of airborne particulate matter as tracers of long-range transport of air pollutants around Japan. J Geophys Res. 1994;99:3717-26.

22. Niisoe $T$, Nakamura E, Harada $K$, Ishikawa $H$, Hitomi $T$, Watanabe T, Wang Z, Koizmi A. A global transport model of lead in the atmosphere. Atmos Environ. 2010;44:1806-14.
23. Clayton CA, Pellizzari ED, Quackenboss JJ. National human exposure assessment survey: analysis of exposure pathways and routes for arsenic and lead in EPA Region 5. J Exp Anal Environ Epidemiol. 2002;12:29-43.

24. Larson T, Gould T, Simpson C, Liu L-JS, Claiborn C, Lewtas J. Source apportionment of indoor, outdoor, and personal PM2.5 in Seattle, Washington, using positive matrix factorization. J Air Waste Manage Assoc. 2004;54:1175-87.

25. Molnár P, Johannesson S, Boman J, Barregård L, Sällsten G. Personal exposures and indoor, residential outdoor, and urban background levels of fine particle trace elements in the general population. J Environ Monit. 2006;8:543-51.

26. Molnár P, Bellander T, Sällsten G, Boman J. Indoor and outdoor concentrations of PM2.5 trace elements at homes, preschools and schools in Stockholm, Sweden. J Environ Monit. 2007;9:348-57.

27. Bonanno LJ, Freemen NCG, Greenberg M, Lioy PJ. Multivariate analysis on levels of selected metals, particulate, atter, VOC, and household characteristics and activities from Midwestern states NHEXAS. Appl Occup Environ Hyg. 2001;16:859-74.

28. Japan Waterworks Association. Database of Water Quality of Aqueduct (in Japanese); 2008. Available at: http://www.jwwa.or. jp/mizu/index.html. Accessed 29 July 2011.

29. Suzuki H, Katsuki Y, Ogawa H, Suzuki K, Matsumoto H, Yasuda $\mathrm{K}$. Concentration of trace elements in bottled drinking water (in Japanese with English abstract). Shokuhin Eiseigaku Zasshi. 2000;41:387-96.

30. Sasaki H, Hara C, Sugahara T. The properties of mineral waters in the domestic market (2) (in Japanese with English abstract). Nihon Shokuseikatsu Gakkaishi. 2011;21:286-96.

31. Shotyk W, Krachler M. Lead in bottled waters: contamination from glass and comparison with pristine groundwater. Environ Sci Technol. 2007;41:3508-13.

32. Takeda A, Kimura K, Yamasaki S. Analysis of 57 elements in Japanese soils, with special reference to soil group and agricultural use. Geoderma. 2004;119:291-307.

33. Environment Agency of Japan. Re-evaluation of reference value of element concentration in soil (in Japanese). Tokyo: Environment Agency of Japan; 2000.

34. Aung NN, Yoshinaga J, Tanaka A. Lead in playground soil: exposure estimation of children via ingestion and contamination source. J Environ Chem. 2004;14:545-53.

35. Takaoka M, Yoshinaga J, Tanaka A. Influence of paint chips on lead concentration in the soil of public playgrounds in Tokyo. J Environ Monit. 2006;8:393-8.

36. Irie K, Maeda N, Yoshida K, Kaniwa M. A basic study on analysis of lead in paint scrapings in school and park equipment (in Japanese with English abstract). Nihon Kasei Gakkaishi. 1997;48:1103-9.

37. Tokyo Metropolitan Government. Guideline of chemicals for children (lead in paint) (in Japanese). Available at: http://www. kankyo.metro.tokyo.jp/chemical/attachement/press_lead.pdf. Accessed 29 July 2011.

38. Lanphear BP, Matte TD, Rogers J, Clickner RP, Dietz B, Bornschein RL, et al. The contribution of lead-contaminated house dust and residential soil to children's blood lead levels. Environ Res. 1998;79:51-68.

39. Su M, Barrueto F, Hoffman RS. Childhood lead poisoning from paint chips: a continuing problem. J Urban Health. 2002;79: 491-7.

40. Hogervorst J, Plusquin M, Vangronsveld J, Nawrot T, Cuypers A, Van Hecke E, et al. House dust as possible route of environmental exposure to cadmium and lead in the adult general population. Environ Res. 2007;103:30-7.

41. Aung NN, Yoshinaga J, Takahashi J. Exposure assessment of lead among Japanese children. Environ Health Prevent Med. 2004;9:257-61. 
42. Fergusson JE, Kim ND. Trace elements in street and house dusts: sources and speciation. Sci Total Environ. 1991;100:125-50.

43. Nakamura Y, Takagi M, Yoshinaga J, Tanaka A, Seyama H, Shibata Y. Elemental composition of Japanese house dust and the source of lead (in Japanese with English abstract). Indoor Environ. 2008;11:11-20.

44. Ishibashi Y, Yoshinaga J, Tanaka A, Seyama H, Shibata Y. Lead and cadmium in indoor dust in Japanese houses-relationship with outdoor sources. Indoor Environ. 2008;11:93-101.

45. Kaido T, Takagi M, Yoshinaga J, Tanaka A, Seyama H, Shibata Y. Factors related to elemental variation in house dust (in Japanese with English abstract). J Environ Chem. 2009;19:87-94.

46. Takagi M, Yoshinaga J, Uematsu A, Kaji M, Seyama H, Tanaka A. Source identification of blood lead of Japanese children by stable isotope analysis (unpublished).

47. Turner A, Simmonds L. Elemental concentrations and metal bioaccessibility in UK household dust. Sci Total Environ. 2006;371:74-81.

48. Chattopadhyay G, Lin KC-P, Feitz AJ. Household dust metal levels in the Sydney metropolitan area. Environ Res. 2003;93: 301-7.

49. Rasmussen PE, Subramanian KS, Jessiman BJ. A multi-element profile of housedust in relation to exterior dust and soils in the city of Ottawa. Can Sci Total Environ. 2001;267:125-40.

50. Tong STY, Lam KC. Home sweet home? A case study of household dust contamination in Hong Kong. Sci Total Environ. 2000;256:115-23.

51. Liciewicz M, Heimburger R, Golimowski J. Granulometry and the content of toxic and potentially toxic elements in vacuumcleaner collected, indoor dusts of the city of Warsaw. Sci Total Environ. 2000;263:69-78.

52. Layton DW, Beamer PI. Migration of contaminated soil and airborne particulates to indoor dust. Environ Sci Technol. 2009;43:8199-205.

53. European Food Safety Authority (EFSA). Scientific opinion on lead in food. EFSA J. 2010;8:1570.
54. National Institute of Health Sciences. Daily intakes of food contaminants from total diet study, 1977-2007 (in Japanese). Tokyo: National Institute of Health Sciences; 2008.

55. Ohno K, Ishikawa K, Kurosawa Y, Matsui Y, Matsushita T, Magara Y. Exposure assessment of metal intakes from drinking water relative to those from total diet in Japan. Water Sci Technol. 2010;62:2694-701.

56. Aung NN, Yoshinaga J, Takahashi J. Dietary intake of toxic and essential trace elements by the children and parents living in Tokyo Metropolitan Area. Jpn Food Addit Contam. 2006;23: 883-94.

57. Niisoe T, Harada K, Hitomi T, Watanabe T, Hung NN, Ishikawa $\mathrm{H}$, Wang Z, Koizumi A. Environmental ecological modeling of human blood lead levels in East Asia. Environ Sci Technol. 2011;45:2856-62.

58. Kaniwa M, Kojima S, Nakamura A. Analysis of lead in paints, paint scrapings, and in some kinds of stationeries intended for use by children (in Japanese with English abstract). Eisei Kagaku. 1981;27:391-8.

59. Kawamura Y, Kawasaki T, Mine S, Mutsuga M, Tanamoto K. Contents of eight harmful elements in baby toys and their migration tests (in Japanese with English abstract). Shokuhin Eiseigaku Zasshi. 2006;47:51-7.

60. Isama K, Kawakami T, Nishimura T. Migration of eight harmful elements from household products made of synthetic resin that infants may swallow by mistake (in Japanese with English abstract). Yakugaku Zasshi. 2011;131:1135-40.

61. Sakai S, Asari M, Sato N, Miyajima A. Lead contained in plastic shopping bags and its substance flow (in Japanese with English abstract). J Environ Chem. 2009;19:497-507.

62. Takagi M, Yoshinaga J, Tanaka A, Seyama H. Isotope ratio analysis of lead in blood and environmental samples by multicollector inductively coupled plasma mass spectrometry. Anal Sci. 2011;27:29-35. 